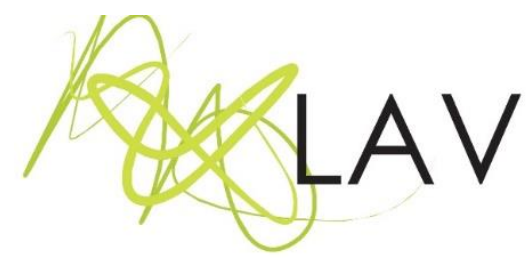

\title{
Imagens da Disney (re)produzindo gênero: \\ Revisão da produção acadêmica (2003-2015) ${ }^{1}$
}

Disney pictures (re)producing gender:

Academic production review (2003-2015)

João Paulo Baliscei

Universidade Estadual de Maringá

Geiva Carolina Calsaii

Universidade Estadual de Maringá

Fernando Herraiz Garcíaiii

Universitat de Barcelona

\begin{abstract}
"Somos o que somos, abrimos caminho através das nossas ações, porque outros, anteriormente, abriram uma trilha que agora permite que continuemos a nossa. Sem o caminho aberto, não poderíamos avançar, ainda que esse caminho siga em outra direção. Por isso sempre avançamos em companhia, inclusive daquilo que já consideramos que não fazemos mais parte, mas que foi um local onde aprendemos a explorar o território diverso e complexo das relações entre as artes e a educação"
\end{abstract}

(Fernando Hernández)

\section{Resumo}

As imagens produzidas pela Disney ensinam indivíduos a ocuparem espaços sociais de acordo com seu gênero. O objetivo é investigar a produção científica brasileira da última década no que diz respeito às relações entre as imagens da Disney, educação e gênero. As nove pesquisas localizadas foram divididas em três grupos: um reunindo os artigos de periódicos científicos; outro, os estudos desenvolvidos junto a Programas de PósGraduação de História, Letras, Antropologia e Estudos Culturais; e outro, os elaborados em Programas de Pós-Graduação em Educação. As pesquisas foram analisadas a partir dos Estudos Culturais e da Cultura Visual, campos de estudos interessados pelas visualidades contemporâneas. Considerou-se que, em comum, as pesquisas localizadas aproximam a Disney a contextos de aprendizagens e denunciam as maneiras como seus produtos sugerem construções específicas de gênero, sobretudo, em relação à feminilidade.

Palavras-chave: Estudos Culturais, educação, masculinidades.

\begin{abstract}
The images produced by Disney teach individuals to occupy social spaces according to their genre. The objective is to investigate the Brazilian scientific production of the last decade regarding the relations between Disney images, education and gender. The nine
\end{abstract}

${ }^{1}$ Estudo realizado com apoio financeiro da Capes/ Programa Doutorado Sanduíche no Exterior/ Processo no $\{$ 888881.131578/2016-01\}.

Revista Digital do LAV - Santa Maria - vol. 10, n. 3, p. 156-178 - set./dez. 2017 ISSN 1983 - 7348 
situated researches were divided into three groups: one bringing together articles from scientific journals; another, the studies developed in the Graduate Programs of History, Letters, Anthropology and Cultural Studies; and another, those elaborated in Graduate Programs in Education. The researches were analyzed under the perspectives of Cultural Studies and Visual Culture, fields of studies interested in contemporary visuals. It has been found that in general, the situated researches relate Disney to contexts of learning and denounce the ways in which its products suggest specific constructions of gender, especially in relation to femininity.

Keywords: Cultural studies, education, masculinities.

\section{Discussões iniciais}

Pela diversão que proporcionam e por serem facilmente associados à infância, frequentemente as visualidades da cultura popular, tais como aquelas que permeiam as revistas, as páginas da web, filmes e desenhos animados, são enxergados com condescendência nos espaços e debates acadêmicos, como se não fossem dignas de análises e provocações científicas. Contudo, como argumentam Giroux (1995) e Steinberg (2015), as mensagens político-culturais intrínsecas ao entretenimento e às visualidades cotidianas são importantes referências para que crianças e jovens, em particular, produzam seus gostos, pensamentos, ações, valores e identidades culturais. Ao oferecerem significados específicos, esses e outros artefatos da cultura popular atuam como Pedagogias Culturais e desestabilizam compreensões tradicionais que insistem em enxergar a escola como a única instituição que educa os indivíduos e que oferece significados para a constituição de sua personalidade.

A expressão Pedagogias Culturais refere-se às imagens e fenômenos culturais que educam os indivíduos sem constituir-se, necessariamente, como atividades ou instituições socialmente reconhecidas por essa intencionalidade. Concordamos com Giroux (1995; 2001a; 2001b) que, assim como as instituições tradicionais de ensino (as escolas, as famílias e as religiões), as Pedagogias Culturais são capazes de educar produzindo, organizando e difundindo conhecimentos específicos, porém, de maneiras associadas ao prazer, ao consumo e à fantasia. Os Estudos Culturais e a Cultura Visual, como campos de investigação em destaque a partir da segunda metade do século XX, manifestam interesses e inquietações pelos fenômenos culturais e pelas maneiras como esses fenômenos representam e/ou tornam invisíveis certos grupos minoritários e historicamente marginalizados. Dentre as manifestações culturais que oferecem pedagogias com as quais as crianças e jovens podem (e são convidados/as) a se identificar, Pillar (2001) e Steinberg (2015) chamam a atenção para os filmes infantis produzidos para o cinema, televisão e web, cujos conteúdos e significados, apesar de não serem espontâneos e despretensiosos, costumam ser considerados inofensivos por parte de familiares e professores/as.

Revista Digital do LAV - Santa Maria - vol. 10, n. 3, p. 156-178 - set./dez. 2017 ISSN 1983 - 7348 http://dx.doi.org/10.5902/1983734828210 
No quesito filmes e animações, as produções da empresa Walt Disney apresentam uma notoriedade especial por seus temas "açucarados" e supostamente "mágicos", capazes de atuar como "máquinas educadoras", como denomina Giroux (2001b).

Além da amplitude de sua distribuição de filmes e animações, a quantidade de crianças que se tornam público cativo desses artefatos culturais só tende a aumentar, como demonstram Bryman (2007), Giroux (2001b), Pillar (2001) e Schor (2009). Em 1955, por exemplo, a Disneylandia, o primeiro parque temático da Disney, foi inaugurado (BRYMAN, 2007) e já cinco anos depois alcançou a cifra de 5 milhões de visitantes por ano - número que em 1990, chegou a 30 milhões (GIROUX, 2001b). Na década de 1990, Pillar (2001, p.13), afirmou que metade da população brasileira era formada "[...] por crianças que passam mais tempo em frente à televisão do que na escola regular, ou na escola de educação infantil" e chamou atenção para a capacidade pedagógica e a aceitação que os filmes e demais produtos da Disney provocavam em crianças e adultos/as. Recentemente, já no século XXI, Schor (2009) considera que a Disney ocupa o primeiro lugar no ranking das empresas que dominam o mercado e o consumo infantil, e com isso revela-nos o crescimento dessa multinacional.

Seja por meio das telas televisivas convencionais ou por meio de suas variações, como os cinemas ou os aparelhos portáteis como smartphones e notebooks, a popularidade dos filmes de animação da Disney e a maneira como eles se multiplicam em produtos, objetos e diálogos cotidianos são tão insistentes e intensas que é comum que crianças e adultos/as considerem os desenhos e animações da empresa como os "de verdade", desconhecendo outras versões das histórias, inclusive as originais, como os contos de Jacob e Wilhelm Grimm (GRIMM, 2012). Para Kincheloe (2001, p. 391-392), no atual contexto cultural, quando empresas consolidadas como a "[...] Disney falam, falam por todos nós" e transcendem a classificação de simples estabelecimentos comerciais.

No que diz respeito à educação, a Disney também têm repercussões diretas na escola, seja por meio da escola-modelo de Celebration - cidade criada pela Disney em 1995, na Flórida, Estados Unidos (GIROUX, 1995, 2001b) -, seja por meio de abordagens pedagógicas meramente contemplativas em que professores e professoras valorizam imagens, filmes e personagens da Disney sem se preocupar em investigar os discursos que tais visualidades valorizam (HERNÁNDEZ, 2000). A Disney também está presente nos espaços escolares na proliferação de imagens e personagens estampados em cadernos, bolsas, adesivos e demais objetos próximos ao contexto estudantil, como observa Nunes (2010). A partir das experiências com seus filhos, Giroux (1995; 2001a; 
2001b) pontua que enquanto a educação escolar educa por meio da repetição, memorização e audição exaustivas, os filmes e animações da Disney fazem o mesmo, porém, com aspectos de diversão, tecnologia e dinâmica que os convergem em potências pedagógicas, cujas metodologias são mais prazerosas que as escolares.

Fundada pelos irmãos Walt Disney (1901-1966) e Roy Oliver Disney (1893-1971) em 1923, inicialmente, a empresa estadunidense era referida pelo nome de Disney Brothers Cartoon Studios, e hoje, é reconhecida pelo termo "Disney" - o que, como um apelido, demonstra a popularidade e aceitação que alcançou em diversos países, dentre eles, o Brasil $^{2}$. Tendo conquistado destaque e pioneirismo na indústria de animação com $A$ Branca de Neve e os Sete Anões (1937), a Disney, com o passar dos anos, diversificou suas produções em filmes com atores e atrizes reais. Atualmente, a diversidade de aparatos associados à marca, tais como camisetas, brinquedos, bonés, decorações de festas, livros para colorir, músicas, sites, comidas congeladas, guloseimas, miniaturas, calçados, móveis, pelúcias, desenhos animados, cartões colecionáveis, jogos e mais de dez parques temáticos espalhados pelo mundo, que mobilizam a formação das identidades valorizando determinadas formas de ser.

Em um misto de imagens, sons e movimentos, as personagens masculinas e femininas da Disney também desempenham funções de Pedagogias Culturais e ensinam às crianças, desde a mais tenra idade, quais comportamentos, ações e espaços podem e devem ser ocupados por meninos e meninas. Nas narrativas da empresa, parece ser imprescindível que mulheres e homens e princesas e príncipes, desempenhem funções específicas e que desenvolvam habilidades, sentimentos e gostos culturalmente associados ao seu gênero. Concordamos com Connell e Pearse (2015) que, sob uma abordagem cultural, não são propriamente os atributos físicos ou biológicos que localizam os indivíduos enquanto homens ou mulheres, mas, principalmente, as maneiras como suas diferenças são efetivamente destacadas, representadas e valorizadas, socialmente. O costume que temos de nomear o corpo como masculino ou feminino antes mesmo de seu nascimento, por exemplo, demonstra os processos e expectativas de masculinização ou feminilização intrínsecos à cultura.

Assim, não podemos pensar o ser mulher ou o ser homem como experiências fixadas pela natureza. Mas também não podemos pensá-los apenas como uma imposição externa realizada por meio de normas sociais ou da pressão de autoridades. As pessoas constroem a si mesmas como masculinas ou femininas. Reivindicamos um lugar na ordem de gênero - ou respondemos ao

${ }^{2}$ Conforme Pillar (2001), o Brasil é o país que mais envia caravanas de turistas para o parque da Disney em Orlando, na Flórida. Na década de 1990, por ano, cerca de 400000 brasileiros/as visitaram essa parque da Disney e desfrutam de suas atrações. 
lugar que nos é dado -, na maneira como nos conduzimos na vida cotidiana. (CONNELL E PEARSE, 2015, p. 39, grifos das autoras).

Em concordância com as autoras, enxergamos que os gêneros são construções elaboradas e reelaboradas, sobretudo, nas relações psicossociais que envolvem aspectos subjetivos e os elementos culturais dos contextos em que vivemos. Nesse ponto, é preciso destacar a contribuição das visualidades, enquanto referências que podem legitimar, invisibilizar, denunciar e problematizam o que é tido como adequado e aceitável para cada gênero. Os pensamentos de Louro (2016) se familiarizam com os das autoras citadas por considerar que os contextos culturais oferecem referências a partir das quais os gêneros são construídos e (re)formulados.

Por certo os próprios sujeitos estão empenhados na produção do gênero e da sexualidade em seus corpos. O processo, contudo, não é feito ao acaso ou ao sabor de sua vontade. Embora participantes ativos dessa construção, os sujeitos não a exercitam livres de constrangimentos. (LOURO, 2016, p. 17).

A autora chama atenção para um conjunto de instituições e ferramentas que atuam para a regulamentação da sexualidade e dos gêneros tidos como "corretos", algumas vezes recorrendo a constrangimentos e violências para alcançar seus objetivos. Esses mecanismos, segundo a autora, buscam garantir que a "ordem" e os "modelos" sejam respeitados e seguidos, e que as tentativas de transgressão sejam embaçadas e punidas. Há também, é preciso esclarecer, outros movimentos que investem financeira e artisticamente na produção de materiais que incentivam o debate e a valorização das diferentes identidades sexuais e de gênero. As exposições História da sexualidade (20178) e Guerrilla Girls: Gráfica, $1985-2017$ (2017-8)33; os livros infantis O menino que ganhou uma boneca (2002) e Coisa de Menina (2009)4; as histórias juvenis $O$ menino de vestido (2014) e Over the Rainbow: um livro de contos de fadxs (2016)5; e os filmes $A$ garota dinamarquesa (2015) e Moana: um mar de aventuras (2016) ${ }^{6}$, são exemplos de recursos que podem ser adotados em intervenções pedagógicas.

Considerando que meninos e meninas (trans)formam suas identidades de gênero conforme interagem entre si, com os/as outros, com o conhecimento, com os espaços em que vivem e, em especial para nosso debate, com as imagens da Disney, é

\footnotetext{
${ }^{3}$ Ambas as exposições foram realizadas no Museu de Arte de São Paulo (MASP), entre 2017 e 2018, sob curadoria de Adriano Pedrosa, diretor artístico do museu.

${ }^{4}$ Majô Baptistone é autora de O menino que ganhou uma boneca, publicado pela editora Massini, e Pri Ferrari é autora de Coisa de menina, publicado pela Companhia das Letrinhas.

${ }^{5}$ O menino de vestido é de autoria de David Walliams e foi publicado pela editora Intínseca, e Over the Rainbow, de Eduardo Bressanim... [et al.], publicado pela editora Planeta.

${ }^{6}$ Dirigido por Tom Hooper, A garota dinamarquesa foi indicado a quatro Oscar, na premiação de 2016, e Moana: um mar de aventuras, uma produção da Walt Disney, indicado ao Oscar de melhor animação em 2017.
} 
imprescindível identificar e discutir sobre os corpos, comportamentos e habilidades que essa empresa de entretenimento associa ao feminino e ao masculino.

Como a temática Disney e gênero tem sido abordada na produção acadêmica nos últimos anos? Há investigações por parte de pesquisadores, pesquisadoras e Programas de PósGraduação em Educação? Quais são suas considerações? Esses questionamentos auxiliam na delimitação de nosso objetivo que é investigar a produção científica brasileira da última década no que diz respeito às relações entre as imagens da Disney, educação e gênero. Para isso, realizamos uma revisão da produção acadêmica, isto é, uma categoria de estudo cujo foco é esclarecer "[...] os pressupostos teórico que dão fundamento à pesquisa e as contribuições proporcionadas por investigações anteriores" (GIL, 2002, p. 162).

O excerto de Fernando Hernández, citado na epígrafe deste artigo, remete-nos à importância deste tipo de estudo para o desenvolvimento da pesquisa científica, uma vez que aquilo que nos aflige e/ou que nos impulsiona à curiosidade e à inquietação é também produto de investigações anteriores das quais podemos nos aproximar ou distanciar. Neste processo de revisão, além das buscas realizadas em ferramentas virtuais de pesquisa, comunicamo-nos com autores/as por email e estabelecemos trocas de textos e referências que ampliaram nossa investigação. A revisão foi realizada nos bancos de dados do Scientific Electronic Library Online (SciELO) ${ }^{7}$, da Biblioteca Digital de Teses e Dissertações (BDTD) ${ }^{8}$ e da Coordenação de Aperfeiçoamento de Pessoal de Nível Superior (CAPES) ${ }^{9}$ a partir das possíveis combinações entre as seguintes palavras-chave: "Disney/Walt Disney", "Estudos Culturais", "Cultura Visual/Estudo da Cultura Visual" e "Gênero". Ao final destes procedimentos, com os refinamentos e descartes, entre artigos, Dissertações e Teses, localizamos dez pesquisas que versam sobre a temática propostas, sendo a mais antiga do ano de 2003, e a mais recente, 2015.

Para a apresentação e análise dos dados, separamos as dez pesquisa em três grupos, sendo o Grupo 1, integrado por dois artigos localizados em periódicos científicos ${ }^{10}$; o Grupo 2, por quatro Dissertações e Teses desenvolvidas junto a Programas de PósGraduação em História, Letras, Antropologia e Estudos Culturais; e o Grupo 3, também por quatro Dissertações e Teses, dessa vez, porém, elaboradas em Programas de PósGraduação em Educação, onde aprofundamos nossas investigações. A seguir, discutimos

\footnotetext{
${ }^{7}$ Buscas feitas em 09 de abr. de 2016. Acesso pelo link <http://www.scielo.org/php/index.php>.

${ }^{8}$ Buscas feitas em 02 de mar. de 2016 pelo link <http://bdtd.ibict.br/vufind/>.

${ }^{9}$ Buscas feitas em 02 de mar. de 2016 pelo link <http://www.capes.gov.br/component/content/article?id=2164>

10 Conforme Gil (2002: 45), atualmente, as publicações em revistas científicas representam "[...] uma das mais importantes fontes bibliográficas".
} 
sobre as pesquisas que integram cada um desses grupos e, por último, antes de tecermos nossas considerações, destacamos as convergências que apresentam entre si.

\section{Grupo 1: Artigos localizados em periódicos científicos}

No SciELO, a partir de buscas com os termos "Disney/Walt Disney", "Estudos Culturais", "Cultura Visual/Estudo da Cultura Visual" e "Gênero", localizamos inicialmente 33 artigos nacionais e internacionais abrangendo temáticas como corpo, animações, cinema, feminilidade, desenhos animados e outros temas distantes daquilo que investigamos, como bactérias, bebidas fermentadas, doenças infecciosas, análises químicas, piscicultura e Nordeste brasileiro - isso porque "Disney" foi, por vezes, identificado como nome de autores ${ }^{11}$ ao invés de se referir à empresa multinacional estadunidense. A partir da leitura dos títulos e resumos, verificamos que, desse total, apenas dois artigos (AVERBACH, 2007; IGRESIAS E ZAMORA, 2013) problematizam os modos como os discursos visuais da Disney contribuem para construir e controlar os gêneros. Por isso, como pode ser percebido na Tabela.01, após a leitura dos títulos e resumos, dos 33 artigos encontrados inicialmente, 31 foram desconsiderados em nossa seleção e apenas dois constituem o que denominamos de Grupo 1.

Tabela.01: Grupo 1: Artigos localizados em periódicos

\begin{tabular}{c|c}
\hline Autoria e ano & Produtos da Disney analisados \\
\hline Las Chicas Superpoderosas. Azucar, & \\
flores y muchos colores: ingredientes & Dumbo (1941), Bambi (1942), A Bela e a \\
para una renovada imagen & Fera (1991), Aladdin (1992), O Rei Leão \\
conservadora del "poder" feminino & $(1994)$ e Pocahontas (1995), \\
(AVERBACH, 2007) & \\
\hline La fémina Disney: análisis y evolución & Branca de Neve e os Sete Anões (1937); \\
del personaje femenino encuatro & Peter Pan (1953); \\
películas de la factoría Disney (IGLESIA & A Bela e a fera (1991); \\
E ZAMORA, 2013) & Procurando Nemo (2003) \\
\hline
\end{tabular}

Las Chicas Superpoderosas. Azúcar, flores y muchos colores: ingredientes para una renovada imagen conservadora del "poder" femenino, de autoria de Averbach (2007), foi um dos artigos localizados por nós a partir do termo "Disney" e, por problematizar a construção de gênero nas imagens da empresa multinacional, integra o Grupo 1. Nesse artigo, o objetivo é descrever a forma que a série de desenho animado As Meninas Superpoderosas $^{12}$ repete ideias conservadoras acerca das personagens femininas. Metodologicamente, a estratégia utilizada para analisar a série As Meninas Superpoderosas foi aproximá-la de outras análises tecidas sobre os filmes de animação

\footnotetext{
${ }^{11}$ As pesquisas de Disney Ribeiro Dias, Walt Disney Paulino, Disney Álvarez Concepción e Disney Piro-Ramírez, por exemplo, foram localizadas pelo nome dos autores - que desenvolvem pesquisas nas áreas de bioquímica de fermentações, piscicultura, suicídio e bactérias, respectivamente.

${ }^{12}$ Série criada pelo desenhista e animador Craig McCracken (1971--) e cujo destaque ocorreu, sobretudo, entre a década de 90 e início dos anos 2000 .
} 
da Disney, como Dumbo (1941), Bambi (1942), A Bela e a Fera (1991), Aladdin (1992), O Rei Leão (1994) e Pocahontas (1995).

Na abertura da série, as três meninas protagonistas - Florzinha, Lindinha e Docinho - são apresentadas como resultado de um experimento científico do professor Utônio que pretendia criar "as meninas perfeitas". Para isso, ele combina "açúcar, flores e muitas cores", ingredientes que, conforme Averbach (2007), reforçam as associações tradicionais entre feminilidade e doçura, delicadeza, romance e graça - como se essas qualidades garantissem o título de "menina perfeita". Ocorre que, junto a esses ingredientes, o professor Utônio derrama, acidentalmente, uma boa quantidade da "Substância X" - um elemento misterioso que faz com que, ao invés de "meninas perfeitas", sejam criadas "meninas superpoderosas". Tal divergência, como aponta a autora, permite a interpretação de que "meninas perfeitas" não podem ser heroínas, violentas, rápidas, corajosas, fortes e capazes de errar, tais como são as "meninas superpoderosas".

A oposição entre "meninas perfeitas" e "meninas superpoderosas" é mais evidente na caracterização da personagem Docinho que, ao contrário do que sugere o nome, é apresentada pelo narrador como "a garota mais dura da cidade, a que chuta primeiro e pergunta depois". Por ser uma menina bruta, durona, mal-humorada e explosiva, Docinho, talvez mais do que suas irmãs, distancia-se da ideia de "menina perfeita" e, por isso, segundo a pesquisa, ocupa papéis periféricos e secundários na série e é situada no último lugar da hierarquia de As Meninas Superpoderosas. Outro ponto interessante, destacado por Averbach (2007) é que, apesar de o trio de meninas superpoderosas salvar a cidade e a população, evitando roubos, assaltos e ataques de vilões/vilãs, são os indivíduos masculinos, como o prefeito e o próprio professor Utônio, que detêm o poder e que determinam quando, onde e o quê tem que ser feito. A autora ainda denuncia que, assim como nas animações da Disney em que os/as protagonistas/as geralmente não têm modelos femininos a seguir uma vez que as mães, quando não ausentes, morrem, ou ocupam o papel de vilã, em As Meninas Superpoderosas fica evidente que mulheres só podem ser heroínas durante sua juventude e que, após o casamento ou a maternidade, são os homens quem detêm o poder. Especificamente sobre os filmes de animação da Disney, Averbach (2007, p.56, tradução nossa) reconhece que os papéis femininos têm sido modificados e que em produções como Aladdin (1992) e Mulan (1998), por exemplo, é possível perceber que "[...] as mulheres são mais livres e claramente capazes de resolver problemas, as vezes muito melhor que os homens que a rodeiam". 
O segundo artigo que compõe o Grupo 1 é La fémina Disney: análisis y evolución del personaje femenino en cuatro películas de la factoría Disney. Nele, Iglesias e Zamora (2013, p. 123, tradução nossa) têm como objetivo "[...] extrair evidências acerca de como os Estúdios Disney têm representado a mulher nos longa metragens de animação". Para isso, o autor e a autora adotam como metodologia a perspectiva sociológica do cinema e da Semiótica, destacando que, como documentos culturais, as produções da Disney refletem comportamentos e valores da sociedade, ao mesmo tempo em que intervêm nela, desestabilizando, reforçando e prestando manutenção às normas e convenções sobre feminilidade. Branca de Neve e os Sete Anões (1937), Peter Pan (1953), A Bela e a Fera (1991) e Procurando Nemo (2003) foram as quatro animações selecionadas para investigação, pois, conforme indicado pelo autor e pela autora, destacaram-se entre as preferências e popularidade de 50 estudantes da Universidade Europeia Miguel de Cervantes. Para a análise, extraíram dos quatro filmes os papéis e comportamentos vivenciados pelas personagens femininas principais e secundárias. Conforme apontaram, em A Branca de Neve e os Sete Anões (1937), Branca de Neve e sua Madrasta desempenham papéis de mulher submissa e mulher fatal, respectivamente - assim como Wendy e Sininho, em Peter Pan (1953). Para Iglesias e Zamora (2013), posicionar mulheres como rivais que disputam entre si o amor de um homem ou o status de "a mais bela" é uma característica comum aos filmes hollywoodianos e, apesar disso, não é recorrente nas outras duas animações analisadas, A Bela e a Fera (1991) e Procurando Nemo (2003). Para o autor e a autora, ao mesmo tempo que essas últimas animações não posicionam mulheres como vilãs e nem como rivais, apresentam protagonistas femininas mais complexas e enigmáticas com as quais meninas e meninos podem se identificar. Apesar de Bela, protagonista de A Bela e a Fera (1991) desempenhar funções maternas - como quando se preocupa com a saúde do pai, ou quando se dedica a ensinar "bons modos" à Fera - ela demonstra interesse pela leitura, pela liberdade e por qualidades que vão além da beleza física - por isso, inclusive, é apontada como "estranha" na pequena aldeia francesa onde vive.

Em suas considerações, tanto Iglesias e Zamora (2013), quanto Averbach (2003) reconhecem que, nas animações mais recentes, é evidente que a Disney tem procurado modificar estereótipos e construir personagens femininas mais independentes e complexas, todavia, terminam por apresentar "[...] velhos esquemas em uma embalagem nova" (AVERBACH, 2003, p. 57, tradução nossa). Enquanto Iglesia e Zamora (2013) reclamam que, nas produções da Disney, as mulheres são insistentemente associadas à maternidade ainda que não tenham concebido nenhuma criança, e que são nulas as representações de afetos, amor e amizade entre as personagens femininas, Averbach (2003) supõe que a série As Meninas Superpoderosas segue reproduzindo as 
relações patriarcais já que são os homens - e não as heroínas- que se relacionam com o poder.

\section{Dissertações e Teses localizadas}

Nesse exercício de revisão da produção acadêmica, identificamos 37 Dissertações e Teses na BDTD e 9 no Banco de Teses da CAPES, chegando a um montante de 27 trabalhos quando excluímos as duplicações. Após lermos os resumos e realizarmos os descartes, chegamos a 9 Dissertações e Teses. Por último, durante a leitura flutuante, descartamos uma das Teses localizadas já que a palavra gênero, nesse caso, referia-se à descrição da identidade dos sujeitos participantes e não às características e comportamentos dos/as personagens das animações. Dessa forma, ao final, foram localizadas oito Dissertações e Teses que estabelecem relações entre Disney, educação e gênero, desenvolvidas em distintos Programas de Pós-Graduação, como o de Estudos Culturais, Artes Visuais, História, Letras, Antropologia Social, Estudos Literários e Educação, como demonstramos na Tabela.02.

Tabela.02: Dissertações e Teses

\begin{tabular}{|c|c|c|c|}
\hline Título, autoria e ano & $\begin{array}{c}\text { Produtos da Disney } \\
\text { analisados }\end{array}$ & Tipo & PPG \\
\hline $\begin{array}{c}\text { O Rato vai à guerra - Como o } \\
\text { Mickey Mouse se tornou uma } \\
\text { imagem de poder dos EUA, 1928- } \\
1946 \text { (KRAUSE, 2011) }\end{array}$ & $\begin{array}{c}\text { Curtas-metragem de } \\
\text { animação, protagonizados } \\
\text { por Mickey Mouse } \\
(1929-1941)\end{array}$ & Dissert. & História \\
\hline $\begin{array}{c}\text { Tiana, uma princesa às avessas?: } \\
\text { A representação da personagem } \\
\text { feminina no filme de animação } A \\
\text { Princesa e o Sapo da Walt Disney } \\
\text { (JUNGES, 2011) }\end{array}$ & A Princesa e o Sapo (2009) & Dissert. & Letras \\
\hline $\begin{array}{c}\text { Girando entre princesas: } \\
\text { performances e contornos de } \\
\text { gênero em uma etnografia com } \\
\text { crianças (BUENO, 2012) }\end{array}$ & $\begin{array}{c}\text { As personagens Cinderela } \\
\text { e Mulan }\end{array}$ & Dissert. & $\begin{array}{l}\text { Antrop. } \\
\text { Social }\end{array}$ \\
\hline $\begin{array}{l}\text { O Vilão Desviante: Ideologia e } \\
\text { heteronormatividade em filmes de } \\
\text { animação longa-metragem dos } \\
\text { Estúdios Disney (SANTOS, 2015) }\end{array}$ & $\begin{array}{c}\text { A Pequena Sereia (1989); } \\
\text { Aladdin (1992); } \\
\text { O Rei Leão (1994) }\end{array}$ & Dissert. & $\begin{array}{l}\text { Estudos } \\
\text { Culturais }\end{array}$ \\
\hline $\begin{array}{c}\text { Filmes infantis e a produção } \\
\text { performativa da } \\
\text { heterossexualidade } \\
\text { (SABAT, 2003) }\end{array}$ & $\begin{array}{c}\text { A Pequena Sereia (1989) } \\
\text { A Bela e a Fera (1991) } \\
\text { O Rei Leão (1994) } \\
\text { Mulan (1998) }\end{array}$ & Tese & Educ. \\
\hline $\begin{array}{c}\text { A natureza no desenho animado } \\
\text { ensinando sobre homem, mulher, } \\
\text { raça, etnia e outras coisas mais... } \\
\text { (KINDEL, 2003) }\end{array}$ & $\begin{array}{c}\text { Vida de Inseto (1998) } \\
\text { O Rei Leão (1994) } \\
\text { O Rei Leão II- O Reino de } \\
\text { Simba (1998) } \\
\text { Pocahontas - O encontro } \\
\text { de dois mundos (1995) } \\
\text { Tarzan (1999) }\end{array}$ & Tese & Educ. \\
\hline
\end{tabular}




\begin{tabular}{c|c|c|c}
\hline $\begin{array}{c}\text { A infância no currículo de filmes de } \\
\text { animação: Poder, governo e } \\
\text { subjetivação dos/as infantis } \\
\text { (SILVA, 2008) }\end{array}$ & $\begin{array}{c}\text { Toy Story (1995); } \\
\text { Monstros S.A (2001) } \\
\text { Procurando Nemo (2003); } \\
\text { Os Incríveis (2004) }\end{array}$ & Dissert. & Educ. \\
\hline $\begin{array}{c}\text { Meninas são doces e calmas" : } \\
\text { gênero atro sobre a produção de } \\
\text { (NUNES, 2008) }\end{array}$ & $\begin{array}{c}\text { Imagens das Princesas da } \\
\text { Disney estampadas nos } \\
\text { materiais escolares }\end{array}$ & Dissert. & Educ. \\
\hline
\end{tabular}

A diversidade de Programas de Pós-Graduação localizados indica que os interesses e preocupações com a Disney e com a construção dos gêneros são movimentos investigativos elaborados e exercitados em várias áreas do conhecimento. Além disso, é relevante destacar que das oito pesquisas localizadas quatro delas (50\%) foram desenvolvidas, especificamente, junto a Programas de Pós-Graduação em Educação - o que remete a preocupação que os/as pesquisadores/as da Educação e professores/as têm demonstrado diante das pedagogias culturais ensinadas pela Disney, seus produtos e personagens. Em seus estudos, Giroux (1995; 2001a; 2001b) tem insistido em chamar a atenção de pais, mães, familiares e professores/as para o caráter educativo que permeia as narrativas, personagens e demais produtos da Disney. Como estratégia de problematização das representações estereotipadas, o autor sugere que mais do que prestar atenção às imagens que os/as estudantes levam para a escola, os/as professores/as assumam a iniciativa de propor análises críticas dos filmes e animações da Disney.

Ao tornar visíveis as relações entre poder e conhecimento e, ao mesmo tempo, questionar aquilo que é, com frequência, tomado como natural, os/as professores/as e os/as críticos podem usar os filmes animados da Disney pedagogicamente para que os/as estudantes e outras pessoas possam ler esses filmes dentro, contra e fora dos códigos dominantes em que eles se baseiam. (GIROUX, 1995, p. 64).

Considerando que as Dissertações e Teses desenvolvidas junto a Programas de PósGraduação em Educação integram 50\% das pesquisas que localizamos e que, como área do conhecimento, a educação têm interesses específicos pelos aspectos pedagógicos conferidos à Disney, reunimos os quatro estudos produzidos em outros Programas de Pós-Graduação no Grupo 2, e no Grupo 3, àqueles relacionados à educação, aos quais conferimos especial atenção. 


\section{Grupo 2: Dissertações e Teses desenvolvidas junto a outros Programas de Pós- Graduação}

Este grupo é constituído por quatro Dissertações e Teses, produzidas em Programas de Pós-Graduação de História, Letras, Antropologia e Estudos Culturais. Desenvolvida no Programa de Pós-Graduação em História da Universidade Federal Fluminense, a Dissertação O Rato vai à guerra - Como o Mickey Mouse se tornou uma imagem de poder dos EUA, 1928-1946, tem como objetivo refletir sobre experiências visuais no contexto histórico, político e cultural do final dos anos 1920, até o final da Segunda Guerra, a partir de Mickey Mouse. Pelo viés da Cultura Visual, analisa uma série de curtasmetragens e investiga as maneiras como esse personagem emblemático da Disney ofereceu significados sobre raça, política, nação e gênero no início do século XX. No que diz respeito à categoria gênero, Krause (2011, p. 140), infere que enquanto Mickey é mostrado como aventureiro e corajoso, sua parceira, Minnie, executa tarefas domésticas e frequentemente precisa ser salva. Enquanto lava roupas e desempenha outras funções em espaços internos, Minnie dança e sorri para Mickey demonstrando sua satisfação com os papéis sociais que ocupa e contribuindo assim para "[...] reafirmar visualmente um discurso da situação tradicional da mulher 'dona de casa'".

A segunda pesquisa que integra o Grupo 2, Tiana, uma princesa às avessas?: $A$ representação da personagem feminina no filme de animação A Princesa e o Sapo da Walt Disney, trata-se de uma Dissertação elaborada junto ao Programa de PósGraduação em Letras da Universidade Católica de Pelotas. Nela, Junges (2010) problematiza a construção e as representações de feminilidade na animação $A$ Princesa $e$ o Sapo (2009). Além disso, a fim de debater sobre os estereótipos de gênero e de raça, desenvolve estudos comparativos das características da personagem protagonista da animação, Tiana, em relação ao conto original e a outras três princesas da Disney.

Em Girando entre princesas: performances e contornos de gênero em uma etnografia com crianças, Dissertação desenvolvida junto ao Programa de Pós-Graduação em Antropologia Social da Universidade de São Paulo (USP), Bueno (2012) tem como objetivo entender a forma pela qual as Princesas Disney são lidas e significadas entre as crianças de diferentes classes sociais no que diz respeito à construção e manutenção de suas feminilidades. Em análise do site da marca Princesas Disney, chama atenção da autora a distinção estabelecida entre "Princesas Clássicas" e "Princesas Rebeldes", marcadas, respectivamente por predicativos tradicionais (como o romantismo e a passividade) e transgressores (como a desobediência e a iniciativa). Cinderela ("Princesa Clássica") e Mulan ("Princesa Rebelde") foram eleitas pela autora para demonstrar como, nos filmes e produtos da Disney, a felicidade feminina é associada ao sucesso conjugal e 
à beleza. Metodologicamente, a autora desenvolveu uma pesquisa etnográfica comparativa com crianças de três escolas do interior do Estado de São Paulo e verificou que "ser bonita" e "encontrar um príncipe", por exemplo, são virtudes femininas apreendidas nos e pelos produtos Disney e que se manifestam, inclusive, nos espaços escolares.

Por fim, a Dissertação O Vilão Desviante: Ideologia e heteronormatividade em filmes de animação longa-metragem dos Estúdios Disney, elaborada no Programa de PósGraduação em Estudos Culturais da USP, tem objetivo de analisar criticamente a sutil estratégia discursiva presente em alguns artefatos midiáticos endereçados prioritariamente às crianças. Teoricamente, Santos (2015) encontra respaldo nos Estudos de Gênero, da Semiótica Greimasiana e na Análise de Discurso e problematiza o status de "normalidade" e de "desvio" no que diz respeito às maneiras como a Disney sugere a construção dos gêneros. O autor investiga as representações de dois vilões e uma vilã da Disney - Scar, Jafar e Úrsrula - por serem identificados como transgressores/a do que é esperado de sujeitos masculinos e femininos. Chama atenção para os filmes da Disney como instrumentos de educação moral que, dentre outras pedagogias, associam sujeitos "desviantes" de masculinidades e feminilidades tradicionais à maldade, egoísmo e solidão e, com isso, acabam por produzir e valorizar condutas heteronormativas.

\section{Grupo 3: Dissertações e Teses desenvolvidas junto a Programas de Pós- Graduação em Educação}

As quatro pesquisas que localizamos em Programas de Pós-Graduação em Educação foram reunidas por nós no Grupo 3 e merecem destaque tendo em vista os interesses afetivos e profissionais que manifestamos pela educação. Na Tese Filmes infantis e a produção performativa da heterossexualidade, elaborada no Programa de Pós-Graduação da Universidade Federal do Rio Grande do Sul (UFRGS), Sabat (2003) tem como objetivo analisar os mecanismos postos em ação pelos filmes infantis de animação da Disney para reiterar a heterossexualidade como norma. A autora evidencia que os filmes da Disney operam como mecanismos sociais que buscam garantir que a heterossexualidade seja enxergada como a "norma" e modelo "corretos" de sexualidade. Para a autora, os produtos da Disney são eficientes recursos pedagógicos que ensinam crianças e adultos/as sobre quais comportamentos são adequados e inadequados para meninos e meninas, dentre eles os que envolvem as identidades sexuais ${ }^{13}$.

\footnotetext{
${ }^{13}$ Sabat (2003: 95) entende que "[...] as identidades sexuais dos sujeitos se constituem de acordo com o modo como vivem sua sexualidade, como vivem seus prazeres e seus desejos sexuais".
} 
Nesta lógica, os vilões e vilãs - monstros, bruxas/os, velhos/as e outros seres abjetos em sua aparência ou comportamento - são apontados/as como os/as outros/as, os/as estranhos/as ou os/as desviantes das "normas" de feminilidade e de masculinidade, e também por isso, são isolados/as e repudiados/as nas narrativas Disney. Adepta à perspectiva dos Estudos Culturais e às formulações dos Estudos Feministas e Queer, a autora considera que no que diz respeito à normatização da heterossexualidade, os filmes de animação da Disney integram amplo e eficiente currículo cultural, que inclui a escola, mas que, de forma alguma, limita-se a ela. Em sua potencialidade pedagógica, tais filmes, como observa Sabat (2003), ensinam que a heterossexualidade é a única sexualidade possível; que cores claras e formas arredondadas são associadas à beleza interior; e que se a mulher falar demasiadamente pode prejudicar sua relação amorosa.

Em $A$ natureza no desenho animado ensinando sobre homem, mulher, raça, etnia e outras coisas mais..., Tese também desenvolvida no Programa de Pós-Graduação da UFRGS, Kindel (2003, p.32) tem como objetivo "[...] investigar de que forma os desenhos animados vêm atuando como 'pedagogias culturais' e que identidades têm sido privilegiadas em suas representações". Em suas experiências com o Ensino Superior nos cursos de Pedagogia e Biologia, Kindel (2003) percebeu que desde a pré-escola até o ensino médio, tem sido comum entre os/as docentes recorrer aos filmes de animação infantil, como O Rei Leão (1994) para abordar conteúdos escolares, como corpo, natureza e cadeias alimentares. Nesse sentido, os produtos da Disney são adotados não só como entretenimento, mas também como recursos didáticos a partir dos quais certos conteúdos escolares são abordados. A autora analisa as representações de natureza difundidas por seis filmes, dos quais, cinco são da Disney e com isso, verifica, também, quais são as sexualidades, gêneros, etnias, raças, nações e classes sociais valorizadas pelas e nas imagens criadas pela empresa estadunidense. Metodologicamente, respaldase nos Estudos Culturais para problematizar as maneiras como os cenários naturais, animais e as personagens humanas que vivem em contato com a natureza são apresentados/as nos filmes. Especificamente quanto às representações de gênero, a autora verificou que mesmo nesses filmes cujos cenários são ambientes naturais (florestas, savanas e campos) estabelecem-se associações restritas e estereotipadas. A associação entre maternidade e feminilidade e poder e masculinidade é uma estratégia de representação adotada por todos os filmes analisados, segundo a autora. Em suas palavras, o poder que caracteriza o masculino "[...] diz respeito à força física, à capacidade de organização e a função de defesa do grupo. Já o poder usado para marcar as fêmeas/mulheres é restritos às questões reprodutivas e às de sobrevivência da prole" (KINDEL, 2003, p. 137). 
A Dissertação A infância no currículo de filmes de animação: Poder, governo e subjetivação dos/as infantis, elaborada por Silva (2008), junto ao Programa de PósGraduação em Educação da Universidade Federal de Minas Gerais, apresentou como objetivo analisar as subjetividades disponibilizadas por filmes infantis de animação produzidos pela Disney e pela Pixar. Respaldada nos Estudos Culturais, a autora investiga as maneiras como os filmes narram as infâncias e engendram posições específicas para os sujeitos infantis, convocando-os a assumirem-nas. Considera que, para governar os corpos e condutas infantis, os filmes investem em dois modelos distintos: o da infância-potencialidade - que representa as crianças por personagens inteligentes e cheios de energia; e o da infância-monstro - que produz os sujeitos infantis como agressivos e assustadores. Também identificou nesses filmes a produção e valorização de uma identidade heróica (marcada pela coragem, confiança e amizade) e a referência à família enquanto instituição formada por indivíduos heterogêneos e por arranjos distintos, divergentes da representação tida como "tradicional" (integrada por pai e mãe casados/as e filhos/as). No que se refere à produção de conhecimentos sobre gênero, a autora argumenta que ao mesmo tempo que os filmes representam masculinidades e feminilidades conhecidas pela sociedade e que (cor)respondem aos valores hegemônicos, em certo ponto, também produzem fissuras e divulgam identidades de gêneros emergentes. Sobre o primeiro ponto, considera que diferentes dos filmes da Disney produzidos no século $X X$, as animações analisadas apresentam poucas mulheres adultas e, quando o fazem, posicionam-nas como em papéis coadjuvantes e figurantes de mães, namoradas e secretárias. Ao excluírem as mulheres de narrativas de aventura, essas animações, segundo a autora, acabam por reiterar uma série de características com as quais os sujeitos femininos têm sido tradicionalmente vinculados, como a passividade, a infantilidade, o cuidado do lar e a busca pelo casamento heterossexual. No caso das fissuras provocadas, os filmes representam personagens masculinos em relações afetuosas com seus filhos e sugerem, de maneira ainda tímida e sutil, que mulheres podem tomar a iniciativa e ocupar lugares poderosos.

Por fim, a Dissertação "Meninas são doces e calmas": Um estudo sobre a produção de gênero através da Cultura Visual foi produzida por Nunes (2008) junto ao Programa de Pós-Graduação em Educação da Pontifícia Universidade Católica do Rio Grande do Sul. Nela o objetivo é verificar e problematizar a constituição de identidades femininas através da Cultura Visual, em contexto escolar. Utiliza-se do aporte teórico-metodológico dos Estudos Culturais e da Cultura Visual, e desenvolve Grupos Focais com 25 estudantes da $3^{a}$ série do ensino fundamental de uma escola privada de Porto Alegre. Álbuns de figurinhas, adesivos, capas de caderno e imagens estampadas em mochilas, estojos e outros materiais escolares são alguns dos artefatos visuais que, dentro e fora do espaço 
escolar, segregam as crianças em grupos exclusivos de meninos e meninas e que, por isso, foram debatidos pela autora com o grupo de estudantes. Constituídas também pelas personagens e discursos da Disney, as imagens selecionadas pelos/as estudantes que participaram da pesquisa reforçam e consolidam visões estereotipadas sobre as identidades femininas e masculinas, perpetuando-as. A partir dos eixos "Regulação dos comportamentos femininos", "Produção e desejo de consumo" e "Constituição dos padrões de beleza física", Nunes (2008) se debruça, sobretudo, nas expectativas e predicativos que visualmente são projetados às meninas. Especificamente sobre a Disney, a autora enfatiza o segmento Princesas Disney como produtores de identidades femininas demasiadamente associadas ao corpo magro e branco, ao consumismo e à ideia de amor romântico. Nessa investigação, a autora relata as opiniões dos indivíduos escolares e problematiza com eles a delicadeza, o romantismo, a doçura e outras características que os artefatos culturais e as imagens da Disney atribuem às identidades femininas.

\section{Discussões entre os Grupos 1, 2 e 3}

As dez pesquisas localizadas na Revisão da produção acadêmica realizada por nós têm em comum a compreensão de que as imagens da Disney atuam como mecanismos pedagógicos que ultrapassam as paredes da infância e reverberam também comportamentos, pensamentos e preconceitos de mulheres e homens adultos. Nesses artigos, Teses e Dissertações, os/as autores/as, de maneiras distintas, inferem que nas narrativas e produtos da Disney, as ações, diálogos e imagens insinuam e naturalizam a submissão e obediência feminina aos homens e localizam as personagens femininas em papéis restritos e estereotipados.

Princesas ou não, adultas ou não, humanas ou não, a caracterização das personagens mulheres é composta por vestidos exuberantes, laços de fita, maquiagens, cílios grandes, pálpebras e lábios coloridos e cabelos longos, como se não houvesse outras maneiras de pensar e de ser mulher. É como se bondade, infantilidade, casamento, romance, vaidade e beleza operassem como matrizes na (trans)formação das identidades femininas, sejam elas personagens princesas (NUNES, 2008; BUENO, 2012), superheroínas (AVERBACH, 2007; SILVA, 2008) ou até mesmo animais (SABAT, 2003; KINDEL, 2003; KRAUSE, 2011; IGLESIA E ZAMORA, 2013). Desde os primeiros filmes que a empresa produziu ainda no século $X X$ baseados nos contos de fadas clássicos, até aqueles mais recentes do século XXI, com raras exceções, como aquelas em que as mulheres desempenham papéis de princesas transgressoras (BUENO, 2012) ou de vilãs (SILVA, 2008; SANTOS, 2015), as produções da Disney insistem na criação de personagens femininas frágeis que

Revista Digital do LAV - Santa Maria - vol. 10, n. 3, p. 156-178 - set./dez. 2017 ISSN 1983 - 7348 http://dx.doi.org/10.5902/1983734828210 
precisam da ajuda e do incentivo de homens, animais, fadas madrinhas e personagensobjetos mágicos para resolver seus conflitos e alcançar a "verdadeira felicidade".

Averbach (2007) e Silva (2008) destacam que nas animações da Disney os/as protagonistas/as geralmente não têm modelos femininos adultos a seguir. As mães, quando não ausentes, morrem ou ocupam papéis antagonistas. Uma interpretação possível para essa representação reincidente é a de que, segunda as imagens da Disney, as mulheres só podem ser heroínas durante sua juventude e que, após o casamento ou a maternidade, são os homens quem detêm o poder. Nesse ponto, Iglesias e Zamora (2013) contribuem ao afirmarem que as mulheres adultas são pouco complexas e insistentemente associadas à maternidade nas histórias da Disney. Ainda que não tenham tido filhos/as, essas mulheres cuidam de outros indivíduos dependentes e infatilizados, como pais, amigos/as, irmãos/ãs e animais. Sobre isso, Kindel (2003, p.137) afirma que "[...] a associação entre feminino e maternidade é uma representação que se repete em todos os filmes [...]" analisados por ela.

É preciso destacar também que as conclusões das investigações que localizamos não são simétricas e concordantes sobre a construção de papéis femininos. Enquanto Silva (2008) analisa que Dory, peixe fêmea da animação Procurando Nemo (2003), por seu comportamento infantil e irresponsável reitera estereótipos femininos, Iglesia e Zamora (2013) avaliam que essa mesma personagem é transgressora já que manifesta habilidades que as outras personagens (inclusive as masculinas) não possuem, como ler, pular sobre águas-vivas e falar outras línguas.

Apesar das divergências, identificamos pelo menos cinco pontos reincidentes entre as pesquisas localizadas nessa revisão da produção acadêmica: 1) a aproximação entre os filmes, personagens e demais produtos da Disney com contextos de aprendizagens, seja por meio da utilização deles como recursos didáticos ou pelo reconhecimento de seu potencial pedagógico e dos significados que promovem; 2) o destaque dado aos Estudos Culturais como referencial teórico-metodológico, o que revela a preocupação desse campo de investigação com a produção, leitura e problematização das imagens da cultura popular; 3) a denúncia da associação estabelecida entre feminilidade e maternidade; 4) a consideração de que, nas animações e filmes mais recentes, a Disney têm realizado modificações e desestabilizações nas representações de feminilidade, apresentando mulheres mais independentes e fortes que as personagens clássicas; e 5) a ênfase dada à problematização da feminilidade. 
$\mathrm{Na}$ Figura.01, reunimos imagens de algumas das mulheres da Disney cujos comportamentos, falas, desejos, aparências e habilidades foram analisados pelas pesquisas localizadas nesta revisão. As identidades de Mulher-elástica, Celia Mae, Wendy, Úrsula, Dory, Tiana, Minnie, Bela, Pocahontas, Violeta Pêra, Cinderela, Ariel, Nala, Roz, Mulan e de outras personagens contribuem para que jovens, adultos/as e crianças (re)pensem o que é apropriado ou não à feminilidade.
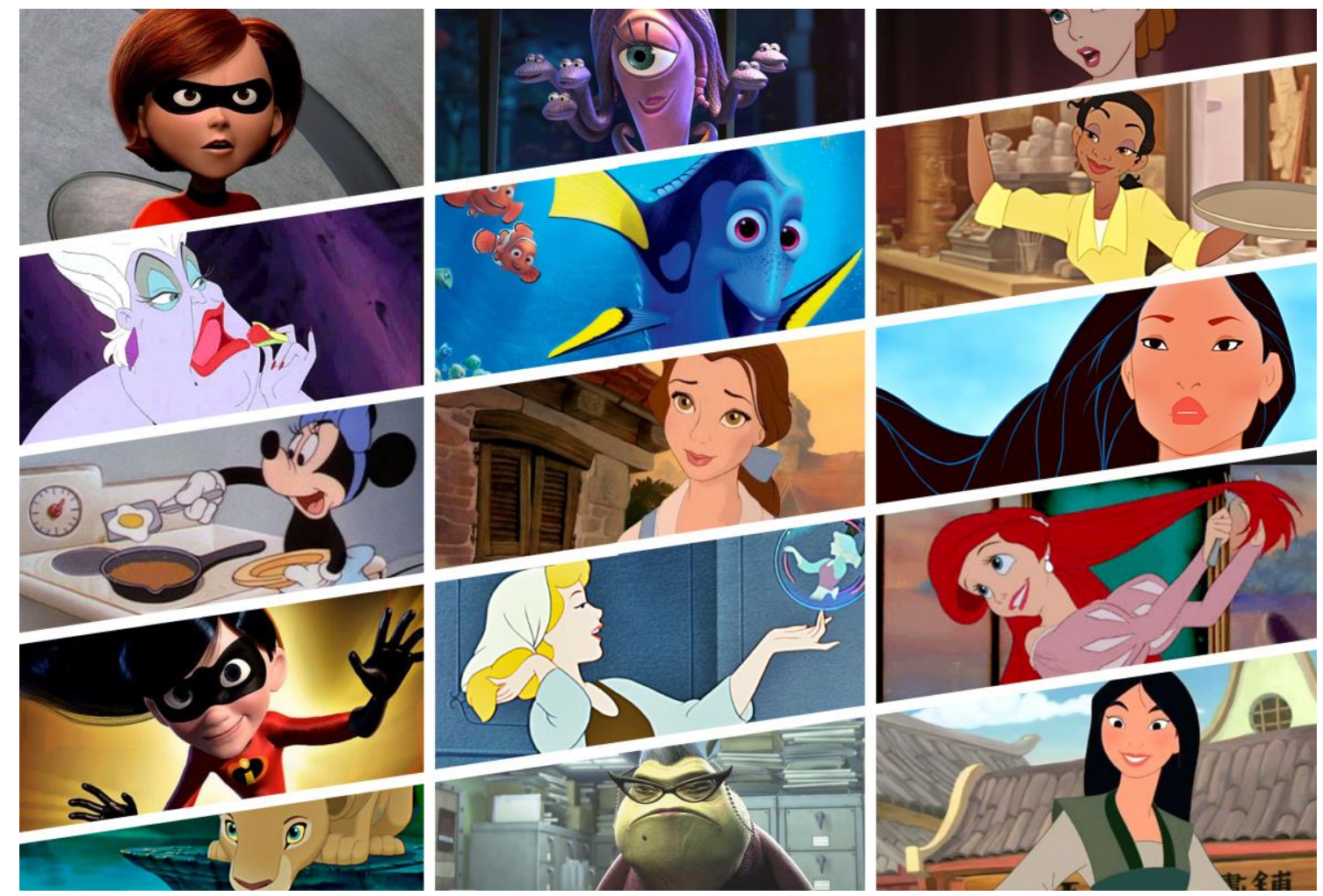

Figura.01: As mulheres da Disney

Fonte: Imagens retiradas da internet. Montagem e elaboração nossas (2017).

Consideramos que, ainda que tragam contribuições sobre as relações entre as imagens Disney, educação e gênero, as autoras e autores localizados/as e citados/as nesse artigo, não se debruçaram especificamente sobre as representações de masculinidades promovidas pelos filmes da Disney. No item 6.8 de sua Tese, Silva (2008) dedica três parágrafos à problematização das maneiras como a Disney contribui para a construção de subjetividades masculinas, neste caso, porém, as análises são secundárias já que o objetivo e os interesses da autora estão voltados para a as subjetividades infantis.

Assim como outros/as pesquisadores/as dos Estudos de Masculinidades (Connell E Pearse, 2015; Badinter, 1993; Kimmel, 1998; Nunes E Martins, 2012) temos desenvolvido pesquisas (BALISCEI, TERUYA E STEIN, 2015; BALISCEI E STEIN, 2016; BALISCEI, CALSA E JORDÃO, 2016; BALISCEI, MAIO E CALSA, 2016) onde destacamos 
artefatos da cultura popular, tais como filmes, publicidades e materiais escolares, certas masculinidades são valorizadas e outras repreendidas. Nesse ponto, como artefato cultural que produz e reproduz personagens masculinos (Figura.02), podemos supor que a Disney também contribui para a legitimar, transformar e/ou censurar masculinidades.
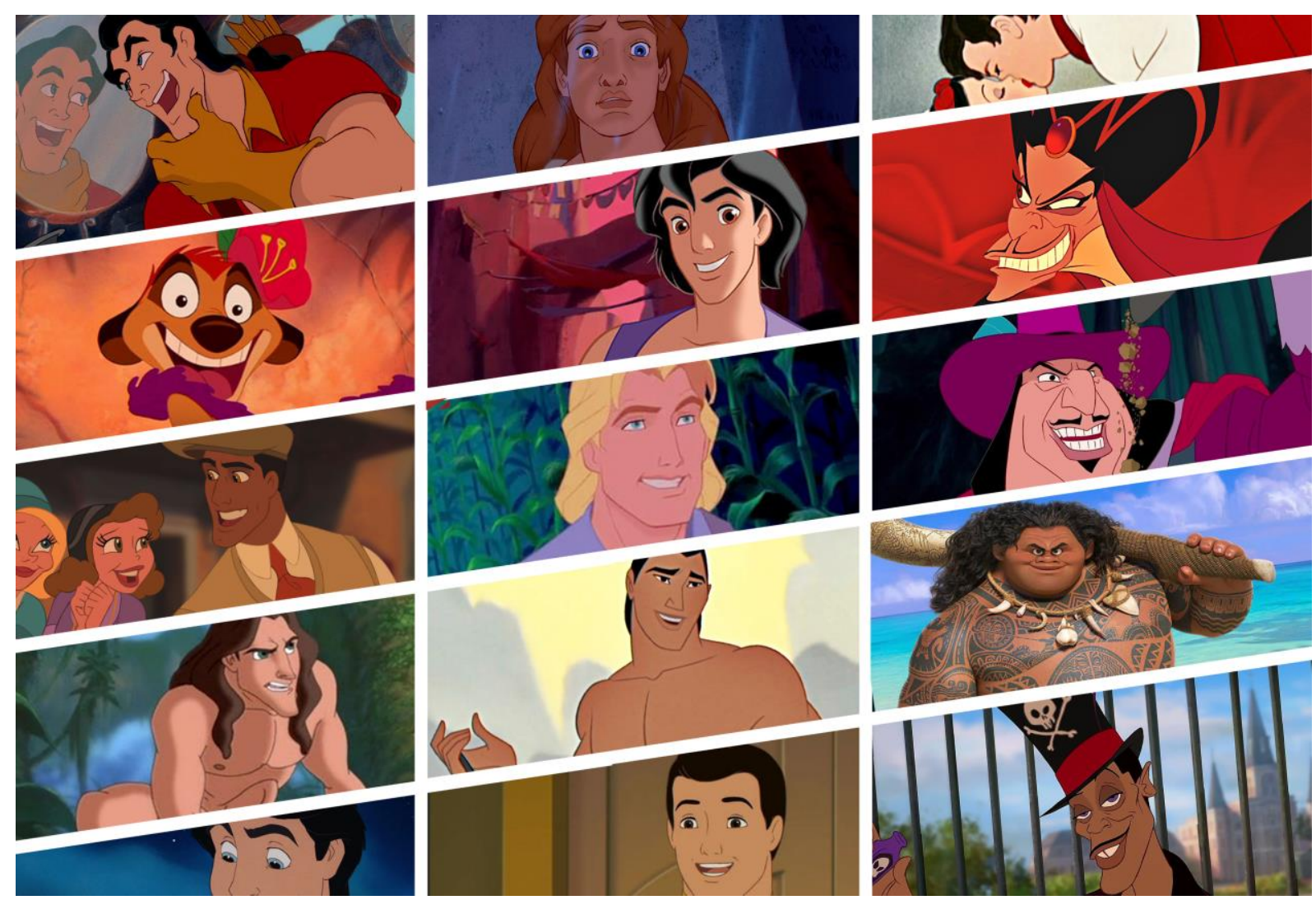

Figura.02: Os homens da Disney

Fonte: Imagens retiradas da internet. Montagem e elaboração nossas (2017).

Quais identidades masculinas são valorizadas nas histórias da Disney? Há comportamentos, corpos e aparências masculinas censuradas? Quais homens são heróis? Quais homens são vilões? Em análise das pesquisas localizadas nesta revisão da produção acadêmica, chamamos a atenção para a construção visual da masculinidade por meio de personagens homens, pois, mesmo não sendo os protagonistas nos filmes e animações da Disney, educam para a constituição das masculinidades infanto-juvenis, apontando valores, características, gestos e conquistas que socialmente fazem com que meninos sejam reconhecidos (e parabenizados) como homens.

\section{Considerações Finais}

Assim como as bússolas ou os mapas das histórias de piratas, os filmes e animações da Disney parecem funcionar como guias que apresentam aos indivíduos contemporâneos, sobretudo às crianças, estratégias e roteiros para que encontrem o grande "x", isto é, 
para que ocupem papéis de gênero específicos e, o mais importante, bem delimitados e não "desviantes".

Com o objetivo de investigar a produção científica brasileira da última década no que diz respeito às relações entre as imagens da Disney, educação e gênero, evidenciamos que, as pesquisas encontradas nessa revisão da produção acadêmica auxiliam na problematização das representações de gênero e, por meio das análises que apresentam, demonstram que no mundo da Disney, homens e mulheres têm lugares específicos, predeterminados e pouco confundíveis. Contudo, das dez pesquisas, nenhuma se propõe a investigar especificamente os papéis e imagens das masculinidades que a Disney faz circular. Tendo em vista que - assim como as feminilidades - as masculinidades são construções sociais que perpassam pelos aspectos visuais, chamamos atenção para a necessidade de problematização das imagens de indivíduos masculinos por atuarem como modelos capazes de formar, transformar e reformar comportamentos, corpos e pensamentos de meninos e homens contemporâneos.

Tendo em vista a ausência de artigos, Dissertações e Teses que se debrucem especificamente sobre as maneiras como a Disney, suas personagens e produtos têm se dedicado a ensinar, construir e a corrigir os comportamentos masculinos, preferimos por finalizar (ou interromper?) nossa discussão com a formulação de perguntas que indicam que nossas inquietações não foram findadas; ao contrário disso, consideramos que formular outras perguntas é uma ação investigativa que contribui para chamar atenção para essa lacuna de pesquisa e para a necessidade de questionar os papéis masculinos que diariamente homens e meninos são convocados a assumir.

Como as personagens masculinas da Disney posicionam e localizam os meninos e homens? Violência, virilidade e rispidez são comportamentos masculinos valorizados por meio das imagens e narrativas da Disney? Há personagens homens delicados, meigos e afeminados? Se sim, quais os papéis e espaços que ocupam nas histórias? Quais valores são exaltados e quais são desqualificados por meio das caracterizações das personagens protagonistas e antagonistas?

\section{Referências}

AVERBACH, Márgara. Las Chicas Superpoderosas. Azúcar, flores y muchos colores: ingredientes para una renovada imagen conservadora del "poder" femenino. Mora, Buenos Aires, v.13, n.2, p. 0-0, jul./dec. 2007. Disponível em <http://www.scielo.org.ar/scielo.php?script=sci_arttext\&pid=S1853001X2007000200002>. Acesso em 12 de abr. de 2016.

BADINTER, Elisabeth. XY, la identidad masculina. Madrid: Alianza Editorial, 1993. 
BALISCEI, João Paulo; TERUYA, Teresa Kazuko; STEIN, Vinícius. Como "ser homem"? Investigando discursos sobre masculinidades. Revista digital do LAV, Santa Maria, v.8, n.4, p.88-104, jan./abr.2015. Disponível em <http://cascavel.ufsm.br/revistas/ojs2.2.2/index.php/revislav/article/view/15098>. Acesso em 10 de jan. de 2016.

BALISCEI, João Paulo; CALSA, Geiva Carolina; JORDÃO, Victor Hugo. O Homem-Malbec e a construção visual da masculinidade. Revista Textura, Canoas, v. 18, n.37, p. 69-89, 2016. <http://www.periodicos.ulbra.br/index.php/txra/article/view/2045>. Acesso em 25 de ago. de 2016.

BALISCEI, João Paulo; MAIO, Eliane Rose; CALSA, Geiva Carolina. Um ovo azul e outro rosa: Pedagogia Kinder e a construção visual dos gêneros e das infâncias. Revista Visualidades, Samambaia, v.14, n. 1, p.284-315, jan./jun., 2016. Disponível em <https://www.revistas.ufg.br/VISUAL/article/view/36655/21584>. Acesso em 01 de set. de 2016.

BALISCEI, João Paulo; STEIN, Vinícius. É difícil ser homem: A (des)construção visual da Masculinidade Hegemônica no filme Bruno. Revista Publicatio, Ponta Grossa, v.24, n.1, p. 63-74, jan./abr. $2016 . \quad$ Disponível em <http://www.revistas2.uepg.br/index.php/sociais/article/view/8256>. Acesso em 15 de ago. de 2016.

BIEGING, Patrícia. Da busca de popularidade às práticas de Bullying. Dissertação (Mestrado) Pós-graduação em Educação, Universidade Federal de Santa Catarina, Florianópolis, 2011.BRYMAN, A. 2007. A Disneyzação da sociedade. Aparecida, Idéias\& Letras, 286p.

BOJUNGA, Sylvia. Abordagem Triangular e Cultura Visual: Possibilidades no ensino de arte complementares ou excludentes? Boletim Arte na Escola. São Paulo, n. 76, p.1, mai./jun. 2015.2 Disponível em <http://artenaescola.org.br/boletim/materia.php?id=75450>. Acesso em 09 de mar. de 2016.

BRYMAN, Alan. A Disneyzação da sociedade. Tradução de Maria Sílvia Mourão Nettp. Aparecida: Idéias \& Letras, 2007.

BUENO, Michele Escoura. Girando entre Princesas: performances e contornos de gênero em uma etnografia com crianças. Dissertação (Mestrado) Pós-graduação em Antropologia Social, Universidade de São Paulo, São Paulo, 2012.

CONNEL, Raewyn; PEARSE, Rebecca. Gênero: uma perspectiva global. São Paulo: nVersos, 2015.

GIL, Antônio Carlos. Como elaborar projetos de pesquisa. São Paulo: Atlas, 2002.

GIROUX, Henry. A dysneização da cultura infantil. In: SILVA, Tomaz Tadeu da; MOREIRA, Antônio Flávio (orgs.).Territórios contestados: o currículo e os novos mapas políticos e culturais. Petrópolis: Vozes, 1995. p, 41-81.

Os filmes da Disney são bons para seus filhos? In: Cultura infantil: a construção corporativa da infância. Shirley R. Steinberg, Joe L. Kincheloe (orgs.). Tradução de George Eduardo Japiassú Bricio. Rio de Janeiro: Civilização Brasileira, 2001a, p. 89-108. 
El ratonzito feroz: Disney o el fin de la inocencia. Traducción de Alberto Jiménez. Madrid: Fundación Germán Sánchez Ruipérez, 2001b.

GRIMM, Jacob; GRIMM, Wilhelm. A Bela Adormecida, In: GRIMM, Jacob; GRIMM, Wilhelm. Contos maravilhosos infantis e domésticos: 1812-1815 [ tomo 1]. Tradução de Christine Röhrig. São Paulo: Cosac Naif, 2012, p. 236-238. HERNÁNDEZ, F. 2000. Cultura visual, mudança na educação e projetos de trabalho.Porto Alegre, ArtMed, $250 p$.

HERNÁNDEZ, Fernando. Cultura visual, mudança na educação e projetos de trabalho. Porto Alegre: ArtMed, 2000.

IGLESIAS, Matías López; ZAMORA, Marta de Miguel. La fémina Disney: análisis y evolución del personaje feminino en cuatro películas de la factoría Disney. Revista Sociedad y Economía, Cali, n.24, p.121-142, ene./jun. 2013. Disponível em <http://www.redalyc.org/articulo.oa?id=99629534006>. Acesso em 11 de abr. de 2016.

JUNGES, Suelen Hernandes Moraes. Tiana, uma princesa às avessas?: Representação da personagem feminina no filme de animação A Princesa e o Sapo da Walt Disney. Dissertação (Mestrado) Pós-graduação em Letras, Universidade Católica de Pelotas, Pelotas, 2011.

KIMMEL, Michael. A produção simultânea de masculinidades hegemônicas e subalternas. Horizontes Antropológicos, Porto Alegre, n.9, 1998, p. 103-117. Disponível em <http://www.scielo.br/pdf/ha/v4n9/0104-7183-ha-4-9-0103.pdf>. Acesso em 13 de mar. de 2017.

KINCHELOE, L. Joe. McDonald's, poder e criança: Ronald McDonald (também conhecido como Ray Kroc) faz tudo por você. In: Cultura infantil: a construção corporativa da infância. Shirley R. Steinberg, Joe L. Kincheloe (orgs.). Tradução de George Eduardo Japiassú Bricio. Rio de Janeiro: Civilização Brasileira, 2001, p. 385-412.

KINDEL, Eunice Aita Isaia. A natureza no desenho animado ensinando sobre homem, mulher, raça, etnia e outras coisas mais... Tese (Doutorado) PósGraduação em Educação, Universidade Federal do Rio Grande do Sul, 2003.

KRAUSE, Katia Iracema. O rato vai à guerra - Como o Mickey Mouse se tornou uma imagem de poder dos EUA, 1928-1946. Dissertação (Mestrado) Pós-graduação em História, Universidade Federal Fluminense, Niterói, 2011.

LOURO, Guacira Lopes. Um corpo estranho: ensaios sobre sexualidade e teoria queer. Belo Horizonte: Autêntica, 2016.

NUNES, Luciana Borre. "Meninas são doces e calmas": Um estudo sobre a produção de gênero através da Cultura Visual. Dissertação (Mestrado) Pós-graduação em Educação, Pontifícia Universidade Católica do Rio Grande do Sul, PUCRS, 2008.

As Imagens que Invadem as Salas de Aula: Reflexões sobre Cultura Visual. 1. ed. São Paulo: Ideias \& Letras, 2010.

NUNES, Luciana Borre ; MARTINS, Raimundo . "Esse é o jeito rebelde de ser": produzindo masculinidades nas salas de aula. Revista Digital do LAV, v. 8, p. 3, 2012.

PILLAR, Analice Dutra. Criança e televisão: leitura de imagens. Porto Alegre: Mediação, 2001. 
SABAT, Ruth. Filmes infantis e a produção performativa da heterossexualidade. Tese (Doutorado). Pós-graduação em Educação, Universidade Federal do Rio Grande do Sul Porto Alegre, 2003.

SANTOS, Caynnã de Camargo. O vilão desviante: Ideologia e Heteronormatividade em filmes de animação longa-metragem dos estúdios Disney. Dissertação (Mestrado) Pósgraduação em Estudos Culturais, Universidade de São Paulo, São Paulo, 2015.

SCHOR, Juliet B. Nascidos para comprar: uma leitura essencial para orientarmos nossas crianças na era do consumismo. Tradução de Eloisa Helena de Souza Cabral . São Paulo: Editora Gente, 2009.

SILVA, Maria Carolina da. A infância no currículo de filmes de animação: Poder, governo e subjetivação dos/as infantis. Dissertação (Mestrado) Pós-graduação em Educação, Universidade Federal de Minas Gerais, Belo Horizonte, 2008.

STEINBERG, Shirley R. Produzindo múltiplos sentidos - pesquisa com bricolagem e pedagogia cultural. In: KIRCHOF, Edgar Roberto; WORTMANN, Maria Lúcia; COSTA, Marisa Vorraber (org.). Estudos Culturais e educação: contingências, articulações, aventuras, dispersões. Canoas: Ed. ULBRA, 2015, p. 211-241.

\footnotetext{
' Graduação em Artes Visuais pelo Centro Universitário de Maringá (2009); especialização em ArteEducação (2010) e Educação Especial (2011) pelo Instituto de Estudos Avançados e PósGraduação; e Mestrado em Educação (2014) pela Universidade Estadual de Maringá. Atualmente é professor no curso de Artes Visuais na Universidade Estadual de Maringá e doutorando no Programa de Pós-Graduação em Educação da referida instituição. É membro do GEPAC - Grupo de Estudos e Pesquisas em Psicopedagogia, Aprendizagem e Cultura - e desenvolve pesquisas sobre Pedagogias Culturais, Cultura Visual, Ensino de Arte e Multiculturalismo.
}

ii Doutora em Educação pela Universidade Estadual de Campinas (2002). Atualmente é professora adjunto da Universidade Estadual de Maringá. Tem experiência na área de Educação, com ênfase em Formação de Conceitos, atuando principalmente nos seguintes temas: cultura, educação, representações sociais, ensino-aprendizagem, construtivismo e intervenção pedagógica.

iii Professor de Pedagogías culturales. Facultad de Bellas Artes / Universidad de Barcelona.

Como citar esse artigo:

BALISCEI, João Paulo; CALSA, Geiva Carolina; GARCÍA, Fernando; Herraiz, Luzinete Carpin. Imagens da disney (re)produzindo gênero: Revisão da produção acadêmica (2003-2015). Revista Digital do LAV, Santa Maria: UFSM, v. 10, n. 3, p. 156-178, set./dez. 2017.

Recebido em: 20 setembro 2017

Aprovado em: 24 novembro 2017

Revista Digital do LAV - Santa Maria - vol. 10, n. 3, p. 156-178 - set./dez. 2017 ISSN 1983 - 7348

http://dx.doi.org/10.5902/1983734828210 